\title{
Using an Exploratory Approach to Help Children with Autism Learn Mathematics
}

\author{
Hui Fang Huang “Angie” Su${ }^{1}$, Leanne $\mathrm{Lai}^{2}$, Herminia Janet Rivera ${ }^{1}$ \\ ${ }^{1}$ Nova Southeastern University, North Miami Beach, Florida, USA; \\ ${ }^{2}$ Nova Southeastern University, Davie, Florida, USA. \\ Email: \{shuifang, Leanne, hr176\}@nova.edu \\ Received June $1^{\text {st }}$, 2010; revised September 23 $3^{\text {rd }}$, 2010; accepted September 30 2010.
}

\begin{abstract}
The exploratory study was carried out at a Choice school located in Davie, Florida. Thirty-four pre-school students with autism and their integrated, typically developing peers received 3 months of mathematics instruction during their regular school day. The purpose of the study was to identify the effective uses of instructional strategies that will impact students' learning. Instruction consisted of both direct and embedded instruction derived from the Project MIND curriculum (Su, 2002). A comparing of the rates of acquisition of math skills for students with autism who received intervention with students with autism who did not receive intervention revealed information about the specific learning abilities of students.
\end{abstract}

Keywords: Autism and Mathematics, Preschool Mathematics, Effective Mathematics Strategies for Children with Autism, Mathematics for Pre-School Age Children with Autism

\section{Introduction (What is Autism?)}

Autism is a complex neurological disorder which impairs one's ability to socialize, communicate, process sensory information, and experience the full range of interests common to most people. In addition to the severe nature of the disorder, the prevalence of autism is increasing. The Centers for Disease Control (2007) reports that as many as 1 in every 150 persons has autism. The severity of the disability coupled with the increasing prevalence rate makes autism a priority among researchers whose focus is to uncover etiologies and effective treatments.

\section{Early Intervention}

While there is no known cure for autism, experts agree that the positive outcomes are highly associated with comprehendsive, early intervention programs (National Research Council 2001). The importance of early intervention for young children with autism has been documented in the literature (Hurth, Shaw, Izeman, Whaley, \& Rogers, 1999; National Research Council, 2001; Rogers, 1999). Rogers (1999) found that some types of early intervention appeared to reduce the debilitating impact of autism and those young children with autism may make gains more quickly than young children with other severe neurodevelopmental disorders. At present, early intervention programs differ markedly in terms of the specific strategies and interventions which are implemented. While the National Research Council broadly recommends early intervention, they also note that less is known about the efficacy of specific strategies for facilitating learning in children with autism. In particular, little attention has been paid to developing programs and evaluating treatment as related to academic skills and the achievement of specific school readiness skills. While some research has been conducted in the area of reading, research on strategies for teaching mathematics to students with autism is limited (National Research Council 2001). A good example is the study conducted by Stahmer, Collings, and Palinkas (2005) where they wanted to provide data on early interventions practices in the classroom and they found special education teachers describing interventions related to speech therapy and occupational therapy/sensory integration. The study provided an important analysis of usage practices however; the authors recommended future investigations to gain a broader understanding of methods and teaching strategies used in Early Childhood Education.

\section{Mathematics}

Teaching mathematics is an important and critical area for several reasons. For one, with the advent of federal legislation including No Child Left Behind Act (2001) there is an increased focus on including children with special needs in general education settings. All children are increasingly expected to participate in high stakes testing and their scores are included in school performance scores. Identification of effective mathematical instructional strategies for students with autism may facilitate success in both standardized testing and inclusion within the regular classroom setting.

\section{Prepare Students in Life Skills}

Second, the ultimate goal of educating children with autism (IDEA 2004) is to prepare students to achieve independence in life functioning and become successful members of the community. Knowledge of basic math skills such as money, measurement, and time are critical for independent functioning ( $\mathrm{Su}$, 2003). It is also necessary to perform basic computational math for independent-living skills such as purchasing, banking, and budgeting. According to Brown and Snell (2000) a key area of academic instruction for students with multiple and severe 
disabilities, including autism, is mathematics; functional math enhances an individual's participation in daily routines and increases opportunities for jobs, volunteer activities, and leisure enjoyment later in life.

Because of the considerable evidence that many students with severe and multiple disabilities, including autism, have difficulty acquiring knowledge of mathematical concepts, it is important that educators use the most effective methods for teaching students mathematical skills. Butler (2001) found in their literature review of mathematics instruction that students benefited from interventions emphasizing frequent feedback, explicit instruction, and practice.

\section{Strategies Used}

Embedded instruction has also been suggested as one strategy that could be used with young children with disabilities in inclusive early childhood special education programs (Harrower, 1999; McDonnell, Johnson, Polychronis, \& Riesen, 2002). In embedded instruction, students are taught skills within the ongoing routines of the classroom setting. Embedded instruction is similar to traditional teaching formats, the teacher implements instructional procedures designed to support the student's acquisition of the target skill. It differs in that the instruction is distributed across the activities that typically occur in the classroom setting rather than being presented one after another with short intertriai intervals. This is accomplished by presenting the instruction when teaching opportunities occur naturally during activities like music, movement, art, cooking, circle time, transition activities and outdoor play.

\section{Objective of Study}

The objective of this study is to evaluate the impact of systematic instruction in mathematics on preschool children with autism. Specifically, this study will aim to answer the following questions:

- Does systematic instruction in mathematical concepts, utilizing direct and embedded instruction, lead to increased knowledge of mathematical concepts and the language of mathematical concepts in preschool-aged children with autism?

- What are the relative contributions of cognitive and visual spatial abilities on the ability to acquire knowledge of mathematical concepts?

- How does the rate of acquisition of mathematical concepts made by students with autism compare to the rate of progress made by same-aged, typically developing peers?

- What modifications to the Project MIND - Math Is Not Difficult ${ }^{\circledR}$ mathematics activities are useful when teaching mathematical concepts to students with autism?

\section{Methodological Design/Data Analysis of Participants}

Four preschool classes serving students with high-functioning autism ( $>70$ on measures of cognition) at the Pre-school were selected to participate. Two of the selected classes were those which exclusively served students with autism. The other two classes were integrated preschool classrooms which served students with autism as well as typically developing peers.

For the purpose of this study, one autism class and one integrated class were randomly assigned to a study group. The other two classes served as the control group. In all, 25 students with autism and 10 typically developing peers participated in the study.

\section{Intervention}

Pre-training: Prior to implementation of mathematics instruction, all teachers received instruction and training on using The Project MIND approach (Su, 2002) a multi-sensory math curriculum, and on direct instruction of math. Classroom teachers participated in after-school training sessions from September through January and received frequent coaching visits and support by project staff to trouble shoot, provide resources, and to insure the curriculum was properly implemented.

Treatment: For students in the study group, systematic instruction in mathematics using strategies based on The Project MIND approach was implemented for a period of 3 months. Systematic instruction was provided using both direct and embedded instructional strategies teaching mathematical concepts such as number sense, and numerical operations.

For direct instruction, students participated in 15-minute, teacher-led instruction sessions daily. Specific objectives taught were individually determined based on the results of pre-assessment data and student's performance level in mathematics at the time of the study.

For embedded instruction, mathematical instruction was embedded into a variety of preschool activities including music, movement, art, cooking, circle time, transition activities and outdoor play utilizing strategies described in the Project MIND approach. The base 10 concept was taught through pairing up number "buddies" (Figure 1).

The students were taught the base ten concepts utilizing a multi-game approach. Students used number tiles to match up numbers which add up to ten (Figure 2). This lays the foundation for algebraic thinking. The students were asked, "Who is 4's best friend?” Then a number sentence was constructed (e.g. $4+$ $=10)$ or ( $+8=10)$

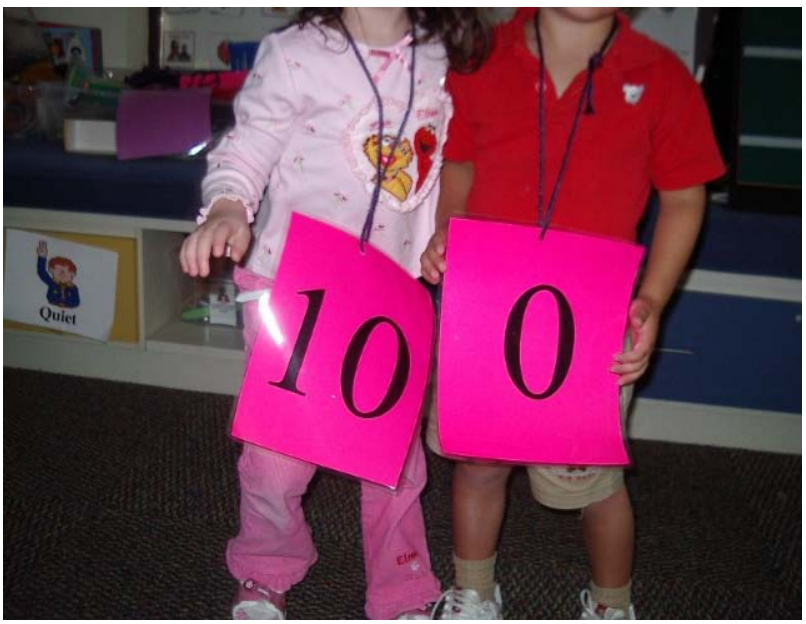

Figure 1.

Best friend large number tiles. 
Concept building continued with a game called "Object Grab Game” (Su, 1988). Students were given three different methods to identify a number - objects, number cards, pictures cards (concrete, semi-concrete, abstract) (Figure 3) and (Figure 4). When prompted, students used any of the three ways to identify the number. For example, the teacher calls "7," the student must quickly find its best Friend 3 using the objects, number cards, or picture cards. If the emphasis was on abstract thinking, then the student who used concrete objects to identify the best friends would receive the highest points.

Students were also given everyday objects to compare (Figure 5) and (Figure 6). Here students identified the larger, smaller, shorter, and or longer of the two objects.

One of the more difficult skills that the students were able to accomplish was to insert missing numbers when given a sequence of numbers. For example, (Figure 8).

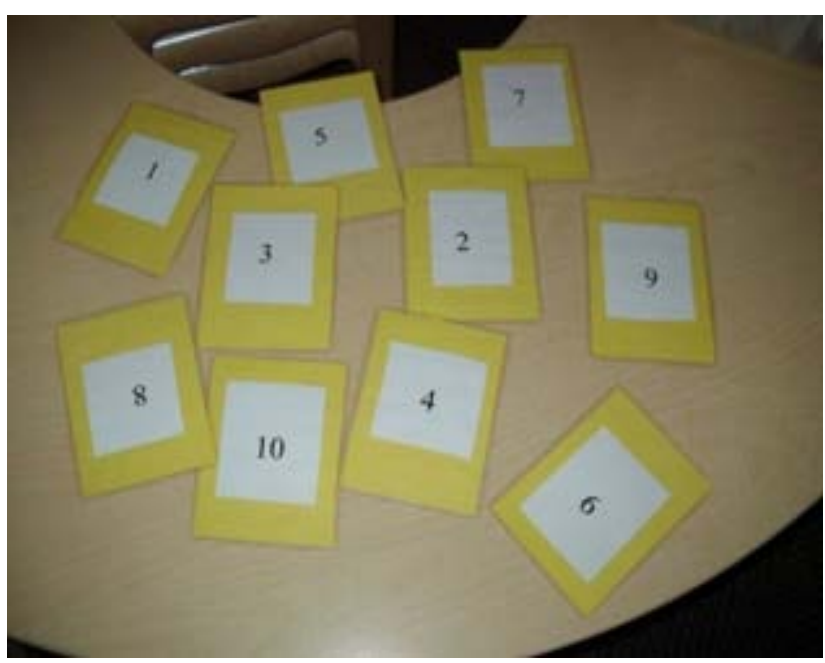

Figure 2.

Number tiles.

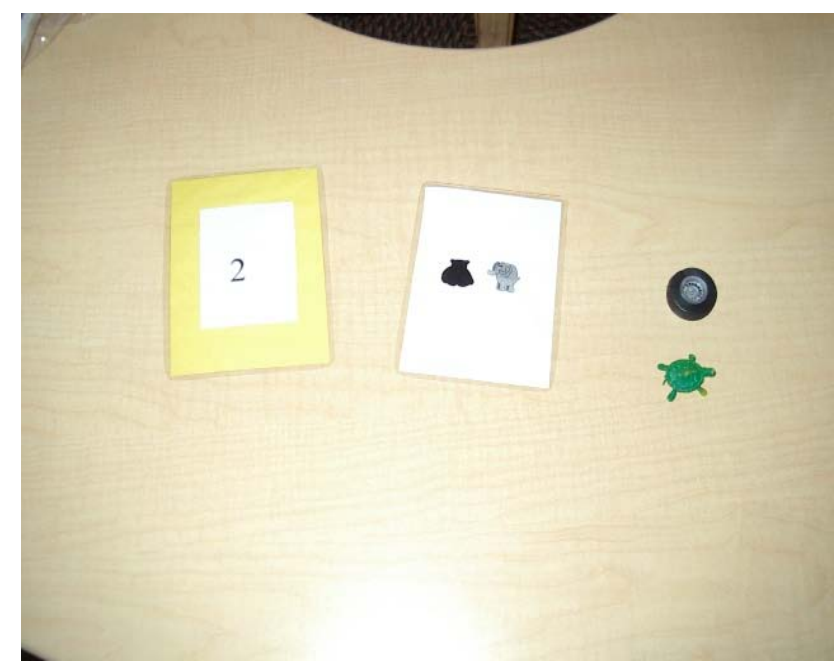

Figure 3.

Object grab game.

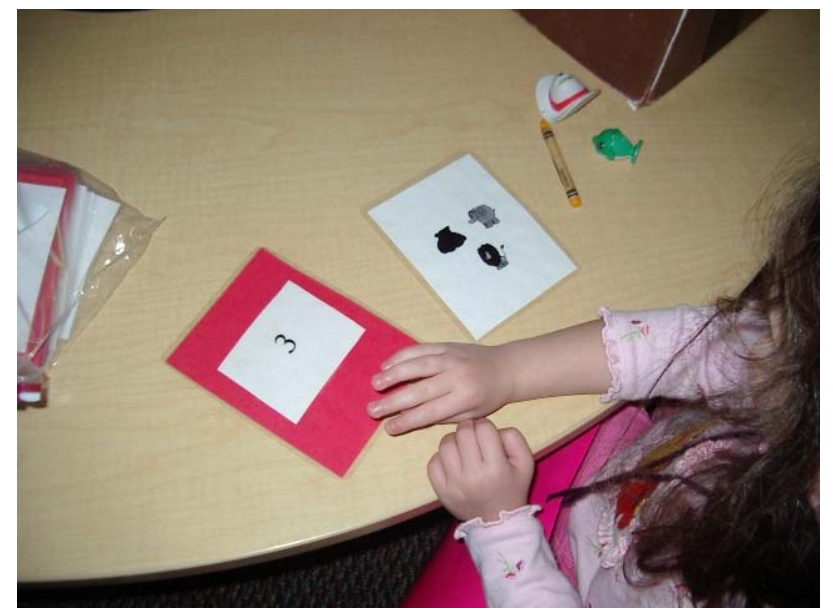

Figure 4.

Student selects a strategy to respond.

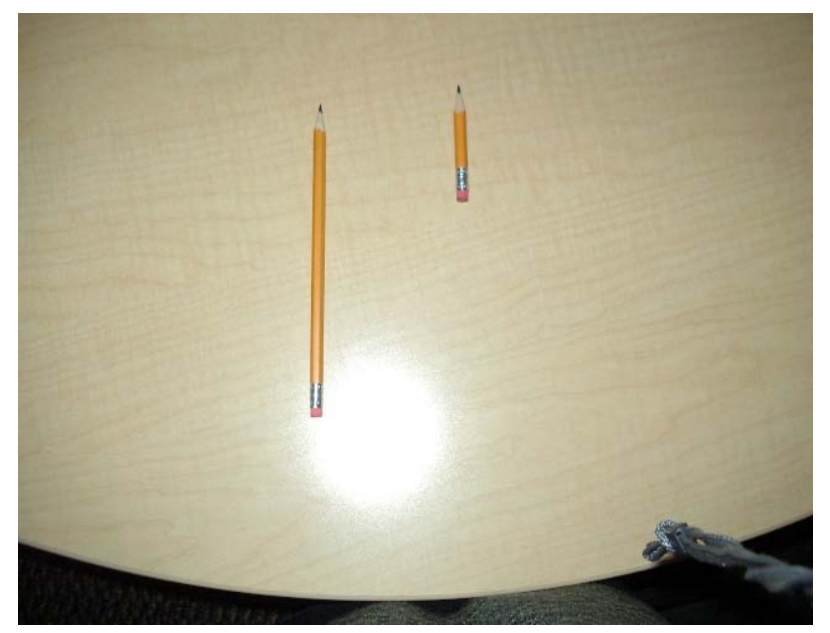

Figure 5.

Longer or shorter.

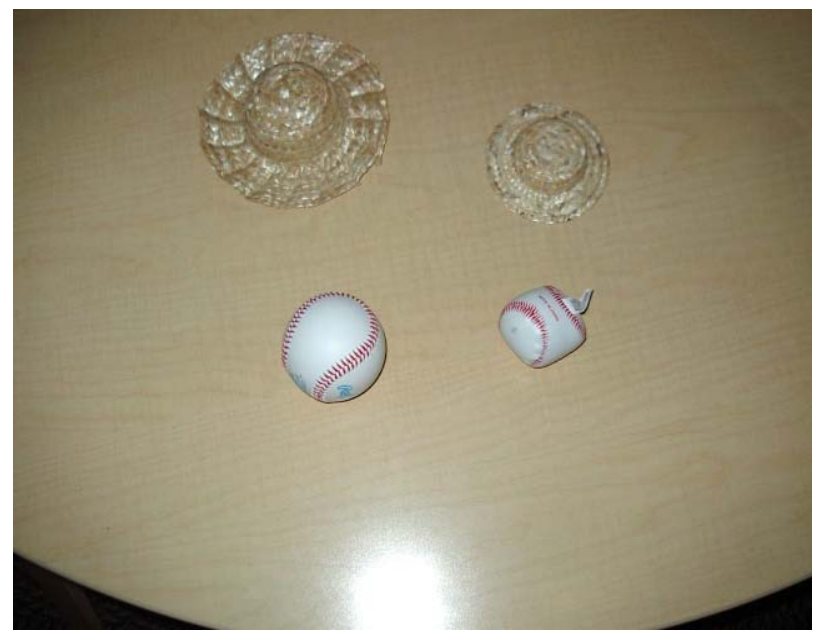

Figure 6.

Larger or smaller. 


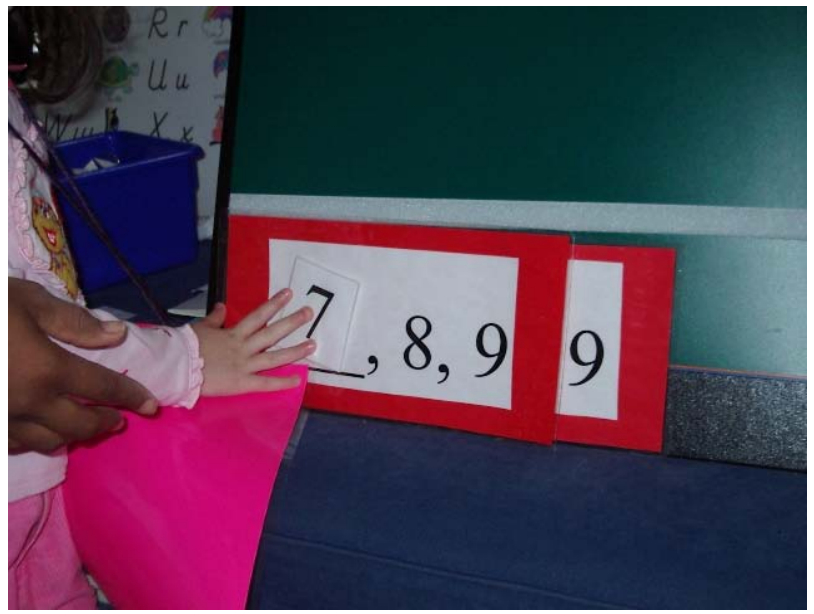

Figure 7.

What number is missing?

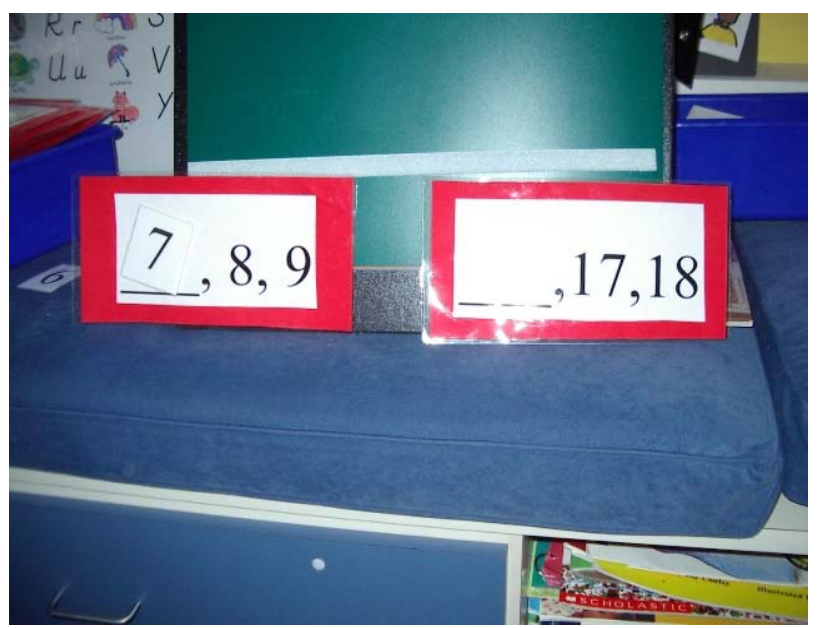

Figure 8.

Students worked on double digits.

\section{The Design}

A quasi-experimental, pre- and post- with control group design was used in the study (Shadish, Cook, \& Campbell, 2002). In this design, both the study and control groups were given pre- and post-mathematics achievement tests using sub-tests from the Hawaii Early Learning Profile (HELP) (which assesses a student's mathematical reasoning and problem solving), and the Bracken Basic Concept Scale - Revised (BBCS-R), (which assesses student's knowledge of the language of mathematical concepts).

\section{Analysis of Covariables}

In addition to a pre- and post-test comparison, students were assessed (prior to intervention) on their cognitive and visualspatial abilities. Cognitive abilities were assessed using the Mullen Scale of Early Learning (MSEL), a comprehensive, individually administered measure of cognitive functioning. Visual-spatial abilities were assessed using the Beery Deve- lopmental Test of Visual Motor Integration (VMI). The VMI and the MSEL were used to identify the relative effects of these variables on acquisition of knowledge of mathematical concepts.

\section{Statistical Analysis}

The Wilcoxin Signed Ranks Test was used to test for a statistically significant difference between pre and post test scores in students' mathematical concepts, relative effects of cognitive ability, and visual spatial ability when exposed to systematic instruction in math. The comparison of the scores of mathematics and cognitive functioning between the study and control groups were made using the Mann-Whitney U test for continuous data and the Chi Square test for discrete data. Additional descriptive trend analyses were used to demonstrate the time series data of each outcome variable. For every test that was conducted, the significance level was 0.05 . Statistical analysis was performed using the Statistics Package for Social Science (SPSS) software program.

Statistically significant differences between pre and post test scores indicated that students with high-functioning autism were able to increase knowledge of mathematical concepts when exposed to systematic instruction in math. In addition, a significant difference between the study and control group showed that systematic instruction in mathematics accelerated learning as compared to student's educated within the guidelines of their typical preschool curriculum.

Statistically significant differences in acquisition of math skills between students with autism and students without autism revealed patterns about the acquisition of math among students with autism. If typically developing peers acquired math skills more readily than students with autism, then results yielded evidence that autism impaired student's ability to acquire academic skills.

\section{Results}

The Mann-Whitney U test was primarily used in this study due to a relatively small sample size in this pilot study. In the paper base assessments, the results show that a significant difference was observed between the study group (with project A+ intervention) and control group (without intervention) in the overall Mullen score (Mann-Whitney $\mathrm{U}, \mathrm{P}=0.000$ ). In particular, a significant difference was shown on all subtests of the Mullen test including visual test (Mann-Whitney $\mathrm{U}, \mathrm{P}=0.002$ ), fine motor test (Mann-Whitney $\mathrm{U}, \mathrm{P}=0.000$ ), expressive language test (Mann-Whitney $\mathrm{U}, \mathrm{P}=0.002$ ), and receptive language test (Mann-Whitney $\mathrm{U}, \mathrm{P}=0.001$ ). A statistically signifycant difference was also found on the H.E.L.P. mathematics scale (Mann-Whitney $\mathrm{U}, \mathrm{P}=0.036$ ) between the study group and control group after intervention. Further, we used the Wilcoxon Signed Rank test to compare the pre- and post-interventions of each test scores to those children with autism assigned to the study group. A significant improvement was shown only on the H.E.L.P. mathematic test (Wilcoxon Signed Rank, P = 0.007).

Prior to the start of the project, we anticipated several challenges:

- The teachers in the study group may potentially share in- 
formation with teachers of the control group. Therefore, teachers in both groups agreed (in writing) not to share teaching strategies during the study period.

- Parents may request switching from the control group to the study group. For this reason, parents had agreed (in writing) to the guidelines of the study.

- Potential attrition of student participants poses a concern. Therefore, any child leaving the center before the project is completed was assessed at the time of departure (when possible) to determine progress, using the assessment instrument designed by the research team. In our study, thirty-four pre-school students with autism and their integrated, typically developing peers received 3-months of mathematics instructions during their regular school day.

\section{Implication of the Study}

Results from this pilot study will help reform the way special and general educators provide mathematics instructions to young children with autism. The strategies can be replicated in other programs serving students with autism. The second stage of the study will include older students with autism, and those with concomitant intellectual disabilities. School districts will be able to implement the program in a variety of classrooms serving children with autism and other severe disabilities.

\section{Acknowledgements}

We wish to thank Dr. Wendy Masi, who allowed the study to be carried out at the Mailman Segal Institute of Nova Southeastern University. Dr. Masi was the former Dean of Mailman Segal Institute for Early Childhood Studies. We also wish to thank the co-principal Investigators of the study, Dr. Melissa N. Hale, Michele Kaplan, and Dr. Sue Kabot for their assistance in selecting sample groups, adjusting activities to help fit the needs of the students, and executing assessments and collecting assessment data of the students involved. We are grateful for all the assistance and guidance provided by the Institute.

\section{References}

Brown, F., \& Snell, M. E. (2000). Instruction of students with severe disabilities. Upper Saddle River, NJ: Prentice Hall.

Butler, F. M., Miller, S. P., Lee, K., \& Pierce, T. (2001). Teaching mathematics to students with mild-to-moderate mental retardation: A review of the literature. Mental Retardation, 39, 20-31. doi:10.1352/0047-6765(2001)039<0020:TMTSWM>2.0.CO;2

CDC (2007). The centers for disease control: Autism spectrum disorders. Retrieved from: http://www.cdc.gov/ncbddd/autism/index.html

Harrower, J. (1999). Educational inclusion of children with severe disabilities. Journal of Positive Behavioral Interventions, 1, 215-230. doi:10.1177/109830079900100404

Hurth, J., Shaw, E., Izeman, S., Whaley, K., \& Rogers, S. (1999). Areas of agreement about effective practices serving young children with autism spectrum disorders. Infants and Young Children, 12, 17-26. doi:10.1097/00001163-199910000-00003

IDEA (2004). Individual with disabilities education act amendments of 1997, Public Law 105-17, 20 USC Chapter 33, Section 1415 et seq. (EDLAW, 1997).

McDonnell, J., Johnson, J. W., Polychronis, S., \& Riesen, T. (2002). The effects of embedded instruction on students with moderate disabilities enrolled in general education classes. Education and Training in Mental Retardation and Developmental Disabilities, 37, 363-377.

National Research Council (2001). Educating children with autism. Washington D.C: National Academy Press.

No Child Left Behind Act of 2001 (2002). Public Law No. 107-110, 115 Stat. 1425.

Rogers, S. (1999). Intervention for young children with autism: From research to practice. Infants and Young Children, 12, 1-16. doi:10.1097/00001163-199910000-00002

Shadish, W. R., Cook, T. D., \& Campbell, D. T. (2002). Experimental and quasi-experimental designs for generalized causal inference. Boston: Houghton Mifflin.

Stahmer, A., Collings, N., \& Palinkas, L. (2005). Early intervention practices for children with autism: Descriptors from community providers. Focus on Autism and Other Developmental Disabilities, 20, 66-79. doi:10.1177/10883576050200020301

Su, H. F. (2003). Don't be puzzled by math. NCSM Journal of Mathematics Education Leadership, 6, 1-7.

$\mathrm{Su}, \mathrm{H}$. F. (2002). Project MIND - Math is not difficult. Journal of Mathematics Education Leadership, 5, 26-29.

$\mathrm{Su}, \mathrm{H}$. F. (1988). Some Ways to get your children to become interested in mathematics. Boca Raton, FL: Project MIND, Inc. 